\title{
Front lines of the COVID-19 pandemic: what is the effectiveness of using personal protective equipment in health service environments? - a systematic review
}

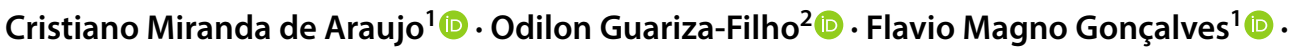

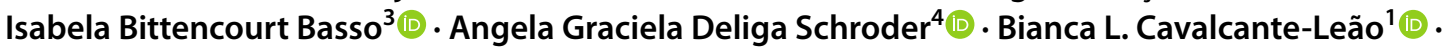

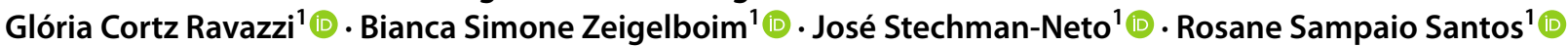

Received: 8 June 2020 / Accepted: 8 January 2021 / Published online: 21 October 2021

(c) The Author(s), under exclusive licence to Springer-Verlag GmbH Germany, part of Springer Nature 2021

\begin{abstract}
Purpose This systematic review aimed to evaluate the effectiveness of the use of personal protective equipment (PPE) in closed environments, similar to waiting or exam rooms of healthcare facilities, in the face of exposure to a bioaerosol.

Methods Combinations of words were selected for six electronic databases and for the gray literature. To consider the eligibility of the studies to be included/excluded, the acronym "PECOS" was used: humans and/or experimental models that simulate aerosol (Population); aerosol exposure and the use of masks/respirators (exposition/intervention); controlled or not controlled (comparison); effectiveness of PPE and the receiver exposure (outcomes); and randomized clinical studies or not, observational or laboratory simulation studies (Studies design).

Results A total of 4820 references were retrieved by the search strategy. Thirty-five articles were selected for complete reading, of which 13 articles were included for qualitative synthesis. A surgical mask or N95 respirator reduced the risk of transmission, even over short distances. The use of masks, even those with less filtering power, when used by all individuals in the same environment is more effective in reducing risk than the use of respirators with high filtering power for only some of the individuals present.

Conclusion The use of mask in closed environments is effective in reducing the risk of transmission and contagion of a contaminated bioaerosol, with greater effectiveness when these devices are used by the source and receiver, regardless of the equipment's filtering power. (PROSPERO 2020 CRD 42020183759).
\end{abstract}

Keywords Aerosols $\cdot$ Personal protective equipment $\cdot$ Environments $\cdot$ Health

Odilon Guariza-Filho

odilongfilho@gmail.com

Cristiano Miranda de Araujo

cristiano.araujo@utp.br

Flavio Magno Gonçalves

flaviomagno93@yahoo.com.br

Isabela Bittencourt Basso

isabelabbasso@hotmail.com

Angela Graciela Deliga Schroder

dra.angela@digitalface.com.br

Bianca L. Cavalcante-Leão

bianca.leao@utp.br

Glória Cortz Ravazzi

gcortz87@hotmail.com

Bianca Simone Zeigelboim

bianca.zeigelboim@utp.br
José Stechman-Neto

stechman1@gmail.com

Rosane Sampaio Santos

rosane.santos2@utp.br

1 Postgraduate Program in Communication Disorders, Tuiuti University of Paraná, Curitiba, Brazil

2 Department of Orthodontics, School of Health and Bioscience, Pontifícia Universidade Católica do Paraná, Street Imaculada Conceição, 1155, Prado Velho, Curitiba, Paraná 80215-901, Brazil

3 Postgraduate Program in Dentistry, Pontifícia Universidade Católica do Paraná, Curitiba, Paraná, Brazil

4 Center for Advanced Studies in Systematic Review and Meta-analysis - NARSM, Curitiba, Brazil 


\section{Introduction}

The transmission of disease between individuals often occurs by the dispersion of droplets of saliva from an infected person through breathing, coughing, speaking or sneezing; in closed environments, this contaminated bioaerosol can be transmitted to another person through the respiratory viruses' entry points (eyes, mouth and/or nose) (Centers for Disease Control and Prevention 2016; Noti et al. 2012; Shiu et al. 2019).

SARS-CoV-2 has a high transmission rate and was classified as a pandemic in March 2020 (Faridi et al. 2020). Similar to SARS-CoV and the influenza virus, an individual can be infected with SARS-CoV-2 by direct contact with contaminated body fluids (Cegolon 2020; Chen et al. 2004; Larson and Liverman 2011). Studies suggest the use of personal protective equipment (PPE), such as surgical masks or $\mathrm{N} 95$ respirators, as an inhalation barrier (Loeb et al. 2009; Siegel et al. 2007) for air control and filtration (Larson and Liverman 2011; Lindsley et al. 2012; Noti et al. 2012).

Smaller aerosol particles are known to be easily inhaled and are capable of being transmitted from short to long range (Tellier 2019), in addition to being suspended in the air for a longer time than larger particles (Gralton et al. 2011). Droplets of larger diameter settle more quickly on surfaces, making them more difficult to inhale; however, these droplets have a greater potential to carry pathogens than smaller droplets, in addition to not penetrating deep into the respiratory tract (Tellier 2019).

Studies indicate that the forms of ventilation where frequent air circulation occurs in environments, such as waiting rooms for health services, are not effective for the total removal of particles generated by bioaerosols but contribute to a gradual decrease in concentration (Lindsley et al. 2012). Individuals are more exposed to this type of contamination indoors (Lindsley et al. 2012), and care must be taken to decrease the risk when these bioaerosols are dispersed in the environment.

Because COVID-19 is a disease in which the virus can be incubated for an average of 5-6 days before presenting any symptoms, the infected patient has the potential to transmit SARS-CoV-2 before symptoms develop (World Health Organization 2020a, b). The World Health Organization (WHO) recommends caution, especially in closed environments, where there may be a circulation of contaminants shed by people with COVID-19, symptomatic or not (World Health Organization, 2020a, b).

Some systematic reviews have addressed the effectiveness of different types of PPE (Bartoszko et al. 2020; Long et al. 2020; Offeddu et al. 2017; Smith et al. 2016; Verbeek et al. 2020); however, to date, none have addressed the effectiveness of this equipment concerning the risk of contamination in closed environments. Therefore, the aim of this systematic review was to analyze the effectiveness of the use of PPE in closed environments, in situations similar to waiting rooms or examination rooms of healthcare facilities, in the face of exposure to a bioaerosol.

\section{Methods}

\section{Protocol and registration}

The protocol for this systematic review was registered on the PROSPERO website (International prospective register of systematic review-Center for Reviews and Dissemination University of York) - CRD42020183759, and the review was performed according to the Preferred Reporting Items for Systematic Reviews and Meta-Analysis (PRISMA) checklist (Moher 2009).

\section{Eligibility criteria}

To consider the eligibility of the studies to be included/ excluded from this review, the acronym "PECOS" was used.

\section{Population (P)}

Studies were included where the population consisted of humans (regardless of age, gender, or ethnicity) and/or experimental models (regardless of design) that simulate the aerosol generated by breathing, speaking, coughing, or sneezing. Animal studies were excluded.

\section{Exposition (E)}

In the case of observational studies, the study population must have been exposed to at least one type of aerosol generated by breathing, speaking, coughing, or sneezing, which may have been generated naturally (humans) or by simulators that resemble the natural production. In interventional studies, the population must have used masks/respirators (homemade, surgical, N95, FFP, FFP2, FFP3) or eye or facial protection as a form of intervention. In both cases, the intervention or exposure must have been carried out in a closed environment, which is physically similar to a health service environment, with the simultaneous presence of an aerosol generator (source) and at least one receiver that breathes in the generated aerosol. In addition, the permanence in the environment must have been transitory (in the same way as the waiting room and exams), excluding nontransitory environments (for example, families in the same residence, or similar situations), or when the study did not make it clear whether or not it was a closed environment. 
Studies were excluded if the population had not been exposed to the generated aerosol, or if the source and the receiver of the aerosol were not in the same environment at the same time.

\section{Comparison (C)}

No inclusion/exclusion criteria were adopted for the control group, and uncontrolled studies were also included.

\section{Outcomes (0)}

The outcomes of interest were as follows:

a) The effectiveness of PPE against exposure to an aerosol generated by speech, breathing, coughing or sneezing.

b) The dispersion and exposure of the receiver and the environment to this aerosol.

Studies that did not assess the outcome of interest were excluded.

\section{Study design (S)}

Randomized or non-randomized clinical studies, observational studies, and experimental laboratory simulation studies were included.

Experimental animal studies, reviews, letters, conference abstracts, expert opinions, or case reports were excluded. There were no exclusion criteria concerning the study language or publication dates.

\section{Information sources and search strategy}

Combinations of words and appropriate truncations have been adapted for the following electronic databases selected as the sources of information: PubMed/Medline, EMBASE, Latin American and Caribbean Literature in Health Sciences (LILACS), Web of Science, Scopus and Cochrane Library. Gray literature was also used as a source of information through Google Scholar, Proquest, and Open Gray (Online resource 1). All searches were performed on May 1, 2020. The references were managed using appropriate software (EndNote ${ }^{\circledR}$ X7 Thomson Reuters, Philadelphia, PA), and all duplicate studies were removed.

In addition to searching the electronic databases and gray literature, an expert (A.L.O.T) on the subject was also consulted via e-mail to verify any possible publications on the subject and to indicate any relevant articles that could be included.

\section{Study selection}

The selection of articles was carried out in two phases, with the total result of records retrieved by the search strategy divided between two pairs (C.M.A/F.M.G and A.G.D.S/ O.G.F). To calibrate the selection of articles, the kappa coefficient of the agreement was calculated for each of the pairs. In the first phase, the titles and abstracts of all references retrieved by the search were independently reviewed. All articles that did not meet the eligibility criteria previously established were excluded at this stage. In the second phase, the full text of the articles selected in the first phase was independently read. Whenever there was some disagreement and the lack of consensus persisted even after discussion, a third reviewer (R.S.S) was involved in the final decision.

To protect the reading of references and guarantee independence and confidentiality in both phases, the Rayyan website was used (http://rayyan.qcri.org), where the reviewers were blinded in all evaluations and a member of the team (I.B.B), who did not participate in the selection, served as the moderator.

\section{Data collection process}

Two reviewers (B.L.C.L and G.M.C.R) independently collected information from the included studies, and this information was discussed with two other members of the team (J.S.N and F.M.G). The data collected consisted of characteristics of the study (author, year of publication, country, title and design of the study), characteristics of the exposure (the type of aerosol generated, contamination, particle size, room size, air humidity and room temperature, PPE used, expiration/breath rate and the distance between the source and the receiver), the results and conclusions. When data were missing or incomplete in the article, attempts were made to contact the authors to obtain relevant unpublished information.

\section{Risk of bias in individual studies}

An adaptation of the Simulation Research Evaluation Rubric (SRR) (17) tool was used to assess the risk of bias in the experimental studies using simulations. This tool includes 16 evaluation items, classified on a scale of 0 to 4 points $(0=$ unsatisfactory and $4=$ excellent $)$, resulting in a total score of 56 points in quantitative or qualitative studies and 64 points in studies with mixed methods. Due to the heterogeneity of the methodologies that could be included in this review, items that did not apply to the study design evaluated were judged as not applicable (NA). To facilitate 
visualization, the scores were transformed into percentages given by the ratio between the total score obtained and the total possible score. Based on quartiles within the rating scale of the score obtained, the studies were classified as having a high risk of bias (0-50\%), moderate risk of bias $(51-75 \%)$, and low risk of bias (76-100\%).

\section{Summary measures}

Any outcome measures were considered, provided the study assessed the outcome of interest.

\section{Results}

\section{Study selection}

A total of 4820 references were retrieved by the search strategy from the six electronic databases, leaving 4316 after the removal of duplicate references. After reading the titles and abstracts (phase 1), a total of 35 articles were selected for complete reading (phase 2), after which 22 were excluded (Online resource 2), resulting in 13 articles included for the qualitative synthesis (Fig. 1). No additional articles were included from the reference lists, gray literature, or consultation with the expert. The value of the kappa coefficient of agreement was $>0.8$ for both pairs, indicating excellent agreement.

\section{Study characteristics}

Of the 13 studies included in this systematic review, all were published in the last 10 years (variation from 2010 to 2019) in English, and 9 were from the United States, 3 were from China, and 1 was from the United Kingdom.

All studies were classified as experimental studies; however, 10 studies used mannequins as a source and receiver simulator, 1 study used a mathematical model to predict the risk of transmission, 1 used a mixed model composed of simulator/mannequins and humans, and 1 study used only humans as the study population.

The areas of the rooms $\left(\mathrm{m}^{2}\right)$ ranged from $2.35 \mathrm{~m}^{2} \times 1.88 \mathrm{~m}$ in height to $10.24 \mathrm{~m}^{2} \times 2.3 \mathrm{~m}$. Two studies presented only the volume $\left(\mathrm{m}^{3}\right)$, and it was not possible to define the exact area of each environment, as the individual measurements (width $\times$ length $\times$ height) of the environment were not provided; two studies did not describe the size of the environment. The temperature varied from 17 to $24{ }^{\circ} \mathrm{C}$, and the humidity varied from 20 to $68 \%$. The size and temperature of the environments, and the distance between the aerosolgenerating source and the receiver, included in this review, are available in Table 1.
The types of masks evaluated in the studies were surgical masks, N95 respirators, face shields, and the combination of an N95 respirator and a surgical mask.

The bioaerosols evaluated in the included studies came from breathing, coughing, and sneezing, but no study evaluated speech-generated aerosols. Most studies used uncontaminated aerosol as the suspension to be dispersed, five studies evaluated influenza virus and only one study used MERS-CoV. The size of the evaluated particles ranged from 0.1 to $>200 \mu \mathrm{m}$. The distance from the aerosol-generating source to the receiver ranged from 0.3 to $2 \mathrm{~m}$. The full description of the included studies is available in Table 1.

\section{Risk of bias within the studies}

Of the 13 articles included, 5 were classified as having a moderate risk of bias, and 8 studies were classified as having a low risk of bias. None of the included studies had a score of $<70 \%$ in the evaluation (Fig. 2).

\section{Results of individual studies}

The only study that evaluated the contaminated aerosol from a virus of the Coronaviridae family was carried out by Adhikari et al. 2019. They predicted the risk of transmission of MERS-CoV in a closed environment where there was movement of several people (healthcare professionals and visitors) in front of an infected patient and observed that an increase in the ventilation rate (air exchange) was an effective measure to reduce the risk for individuals present in the same environment but not for groups exposed to an air route of a short distance. Thus, the N95 respirator was indispensable for reducing the risk of transmission over short distances (Adhikari et al. 2019).

In an environment of $27 \mathrm{~m}^{3}$, the presence of 5 people without a mask increased the concentration of bioaerosol by $107 \%$ within $30 \mathrm{~min}$, and this increase was dependent on the duration people stayed in the environment. However, in this same scenario (environment of $27 \mathrm{~m}^{3}$ occupied by five people), when using an N95 respirator or a surgical mask, the level of bioaerosol increased only $81 \%$ and $31 \%$, respectively. Although $\mathrm{N} 95$ respirators promote greater air filtration, surgical masks appeared to be more effective in decreasing the release of bioaerosol, a difference mainly due to the adjustment and sealing of the mask to the source's face (Xu et al. 2017). The filtering level of the mask, whether used by the source or the receiver, did not play a significant role in reducing exposure, unless the PPE was physically well sealed on the face of the source (Diaz and Smaldone 2010). The greater the adjustment and sealing of the mask to the face, the greater the degree of protection that was provided (Lai et al. 2012), mainly concerning the fit of the mask on the aerosol-generating source (Mansour and Smaldone 


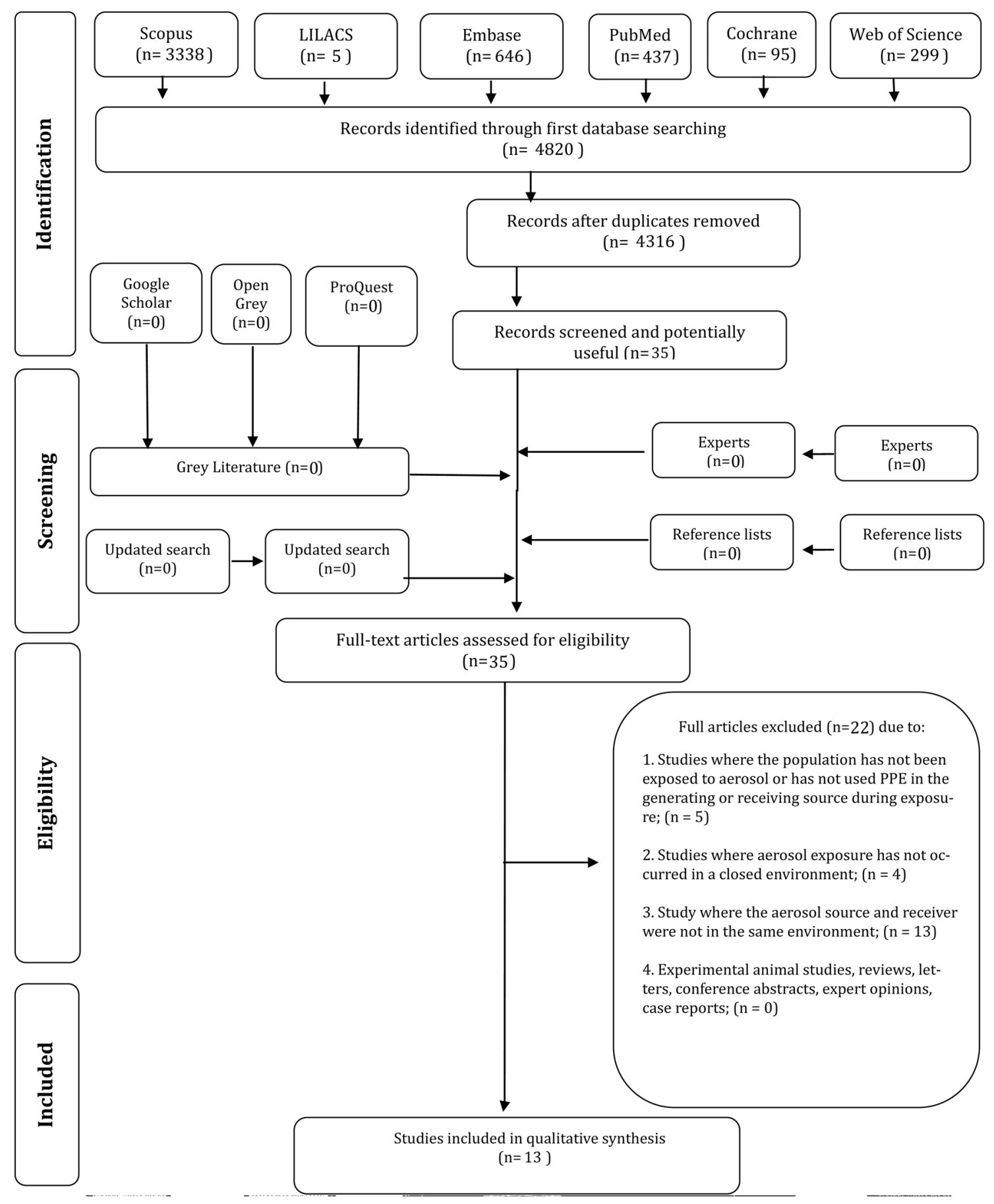

Fig. 1 Flow diagram of literature search and selection criteria

2013). Surgical masks and ill-fitting N95 respirators are not effective in filtering aerosols contaminated by infectious viruses (Noti et al. 2012).

Another result to be highlighted is that the use of a surgical mask by the aerosol-generating source during breathing reached a level of protection in the receiver much higher than that of an N95 respirator (Diaz and Smaldone
2010; Mansour and Smaldone 2013). The N95 respirator had a filtration level of approximately $95 \%$ of the aerosol, but the reduction in exposure by the mask control at its source was significantly greater than the N95 filtering capacity in reducing exposure (Mansour and Smaldone 2013). On the other hand, Patel et al. 2016, observed that the biggest difference with the control of the source with 


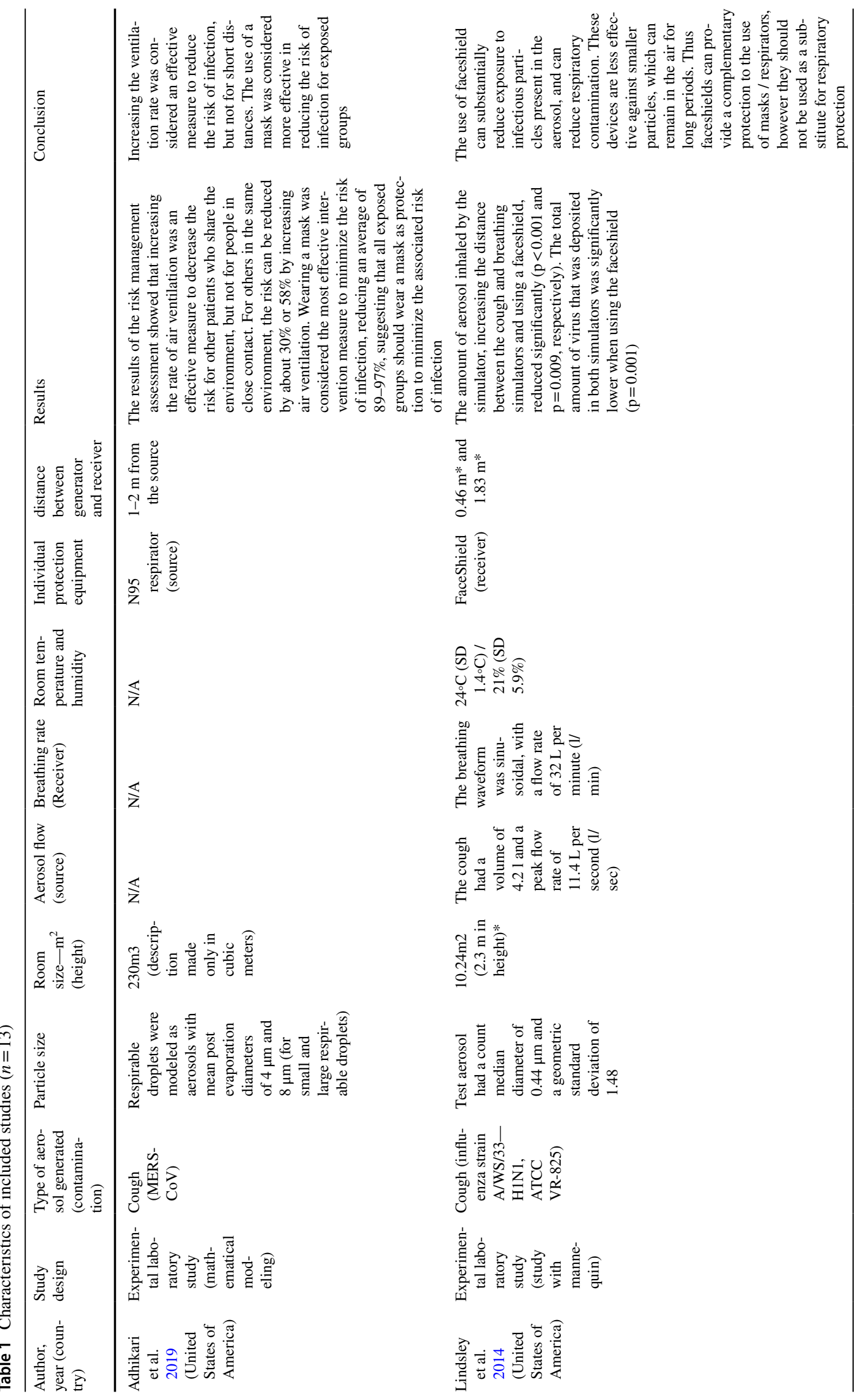




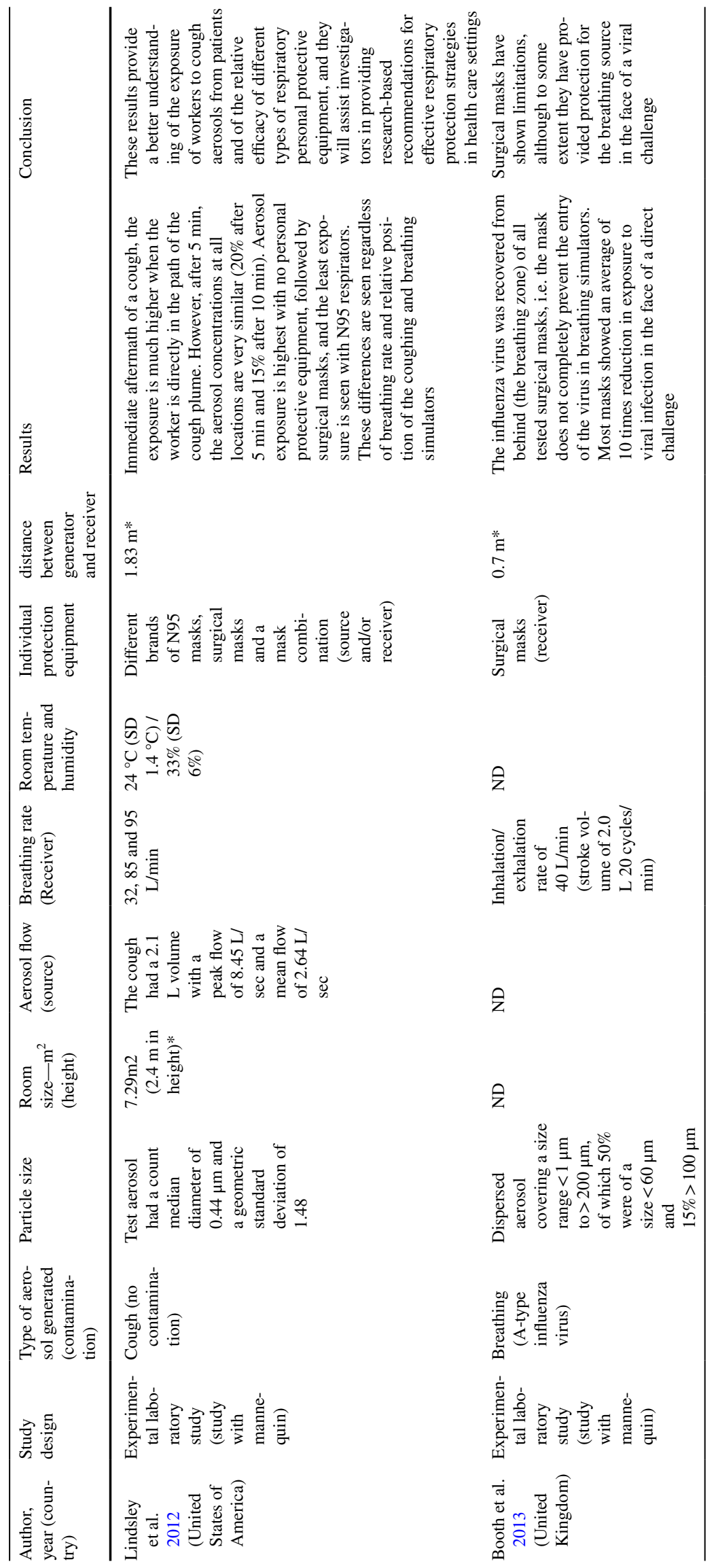




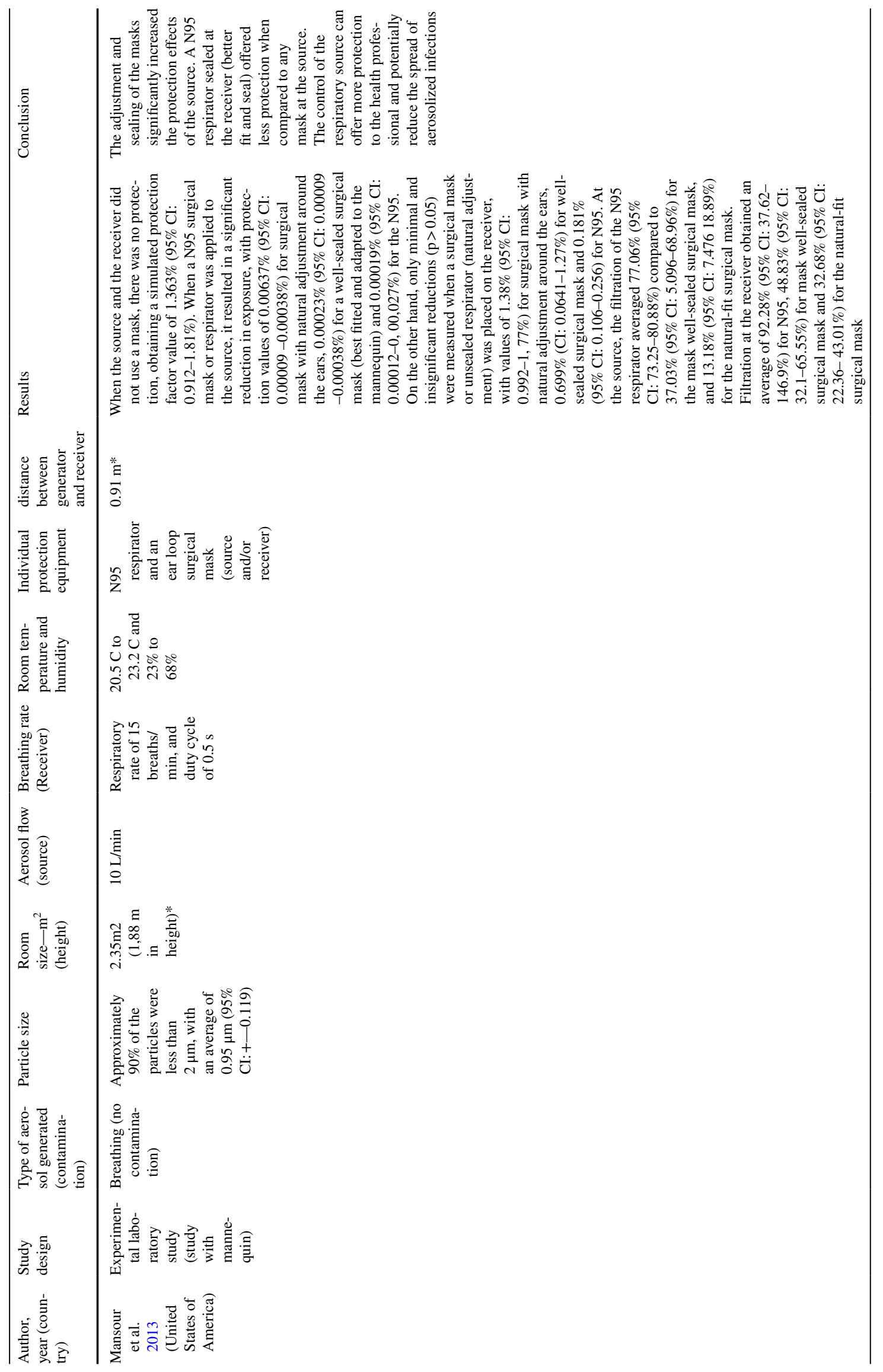




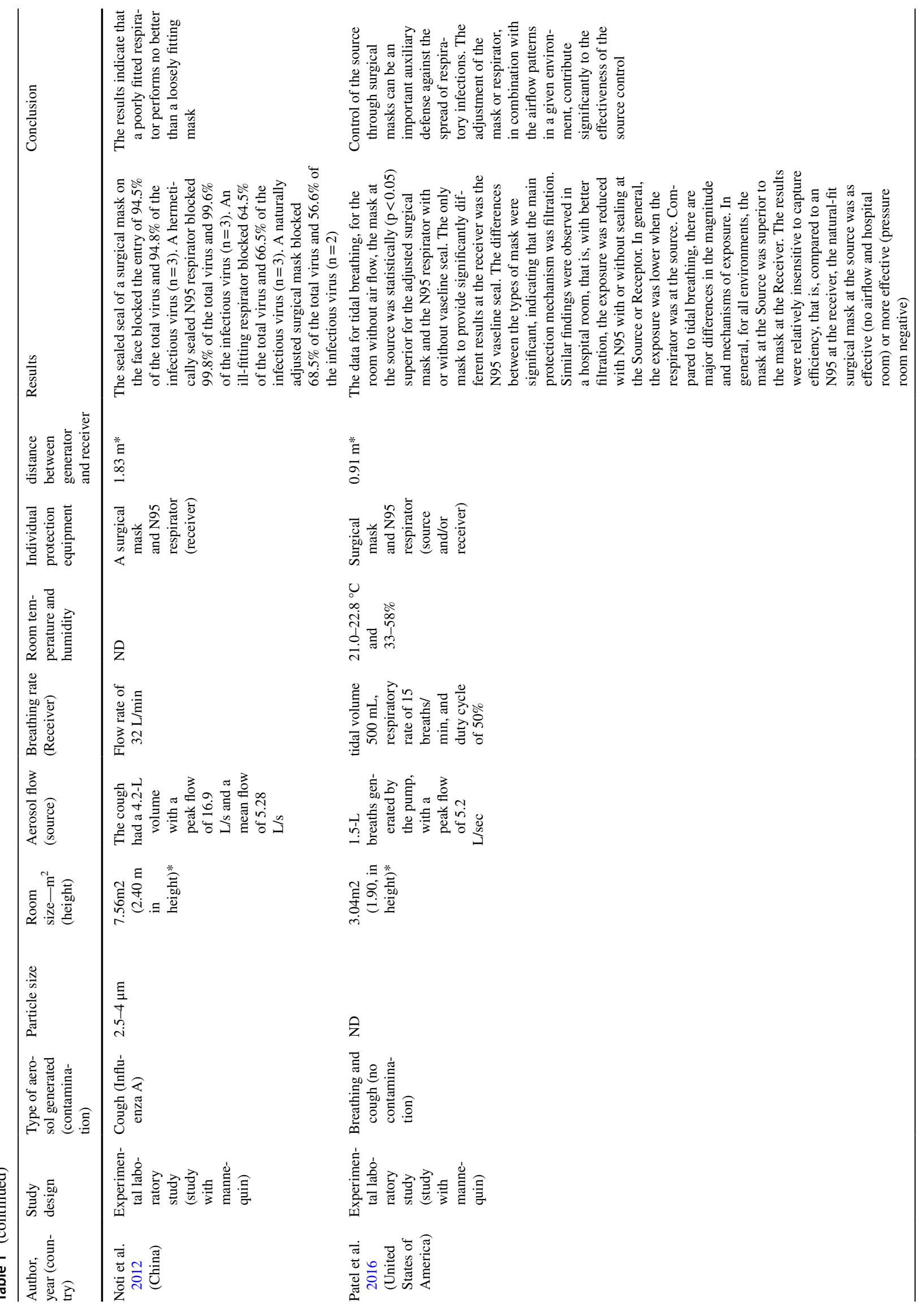




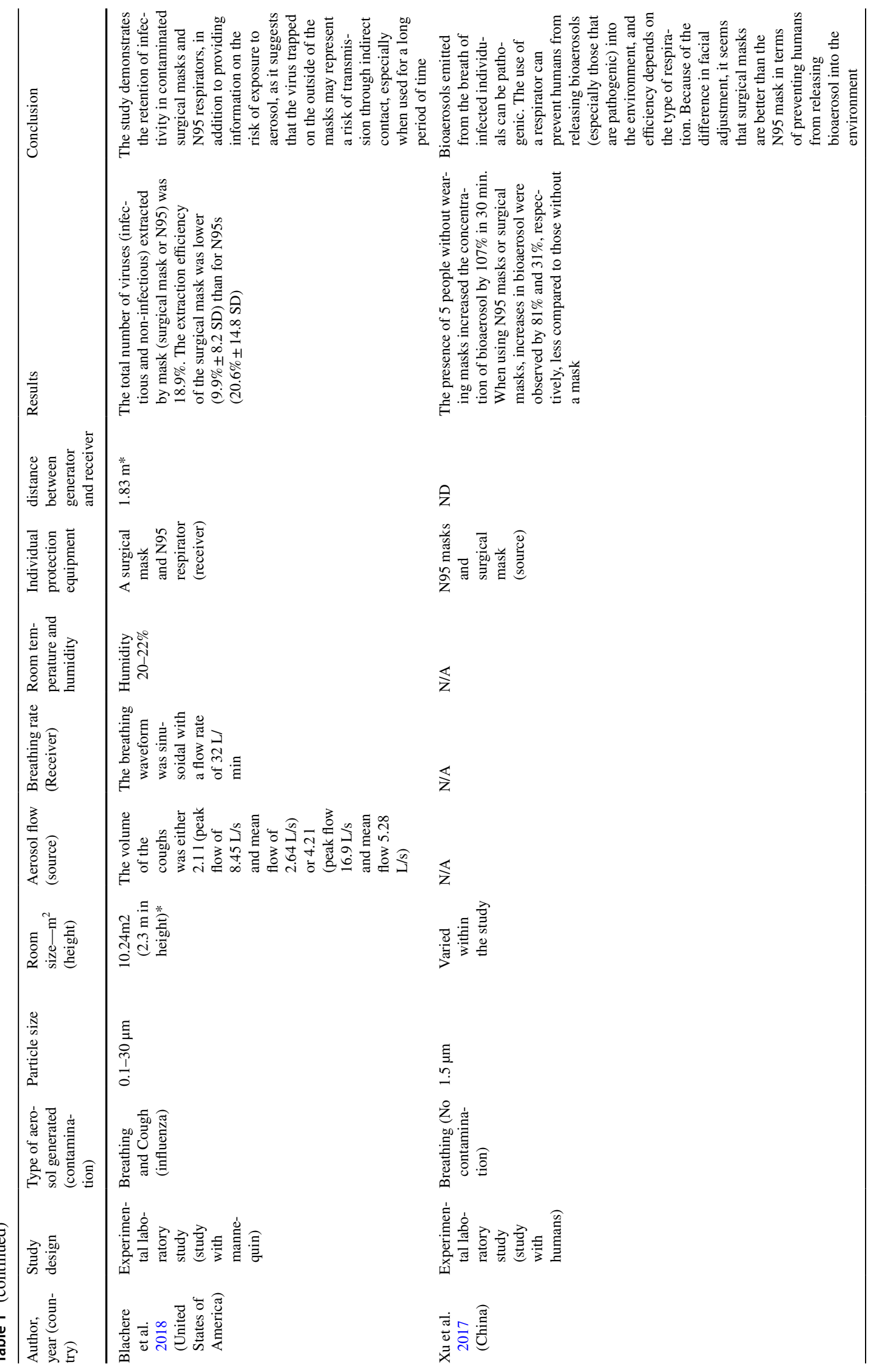




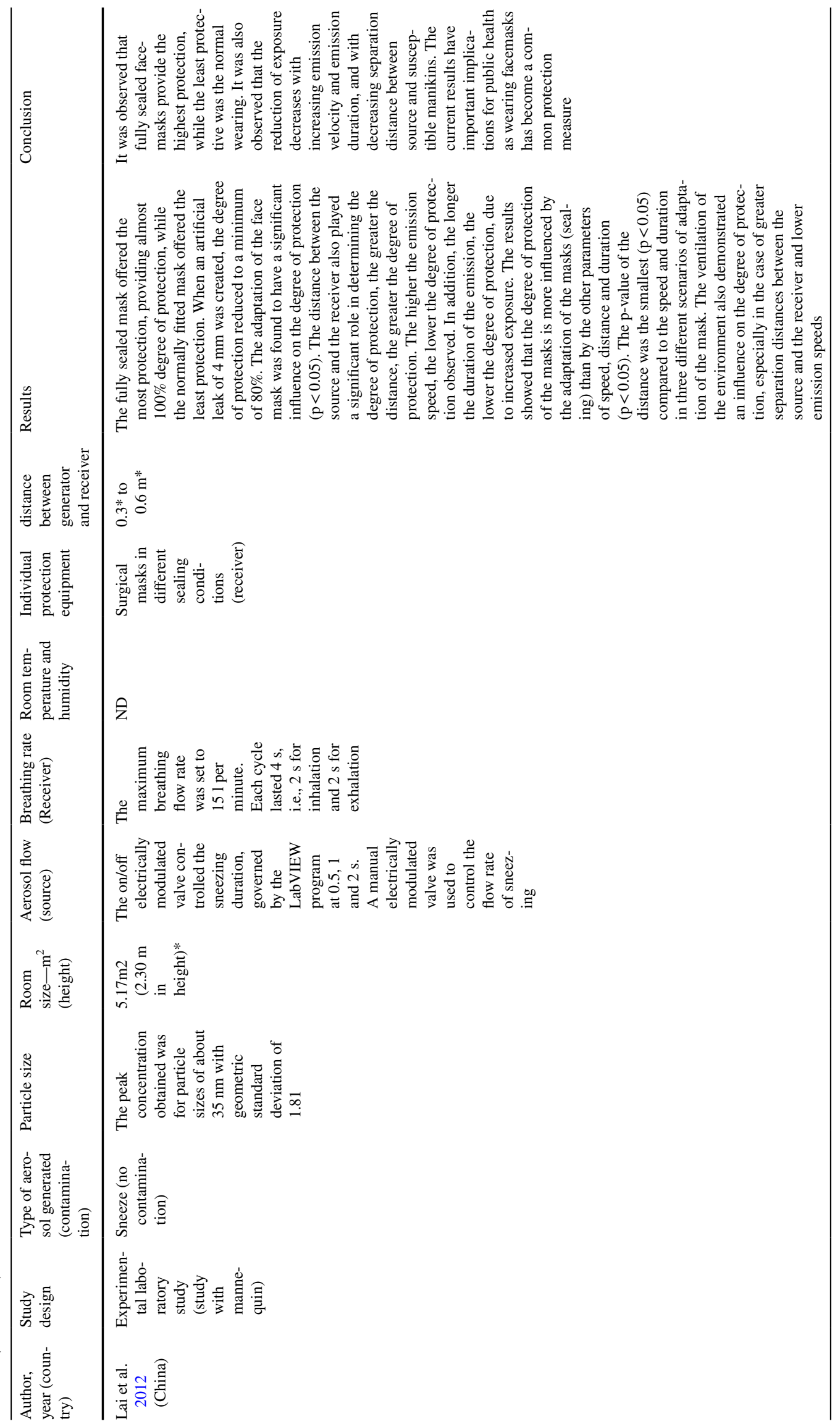




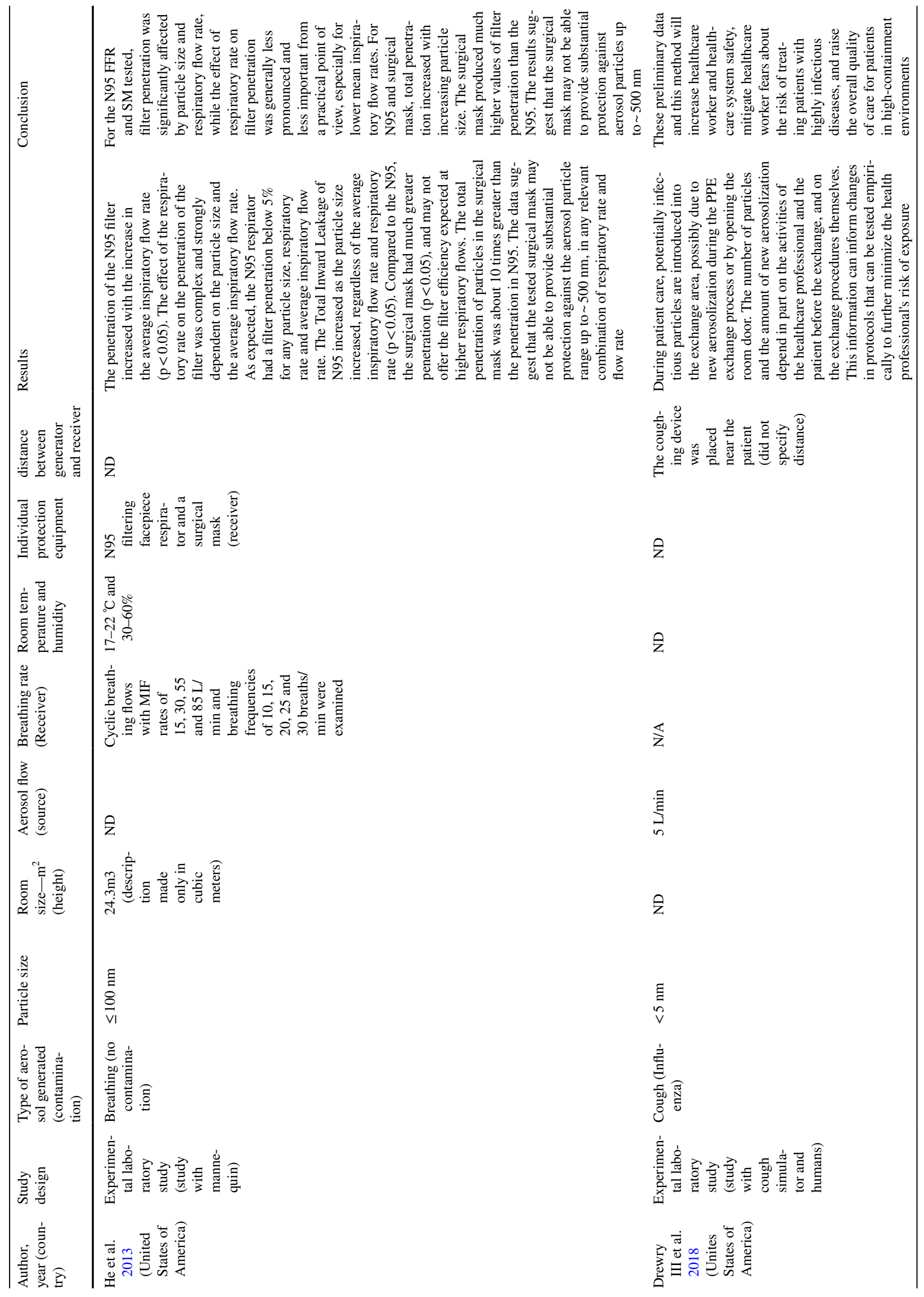




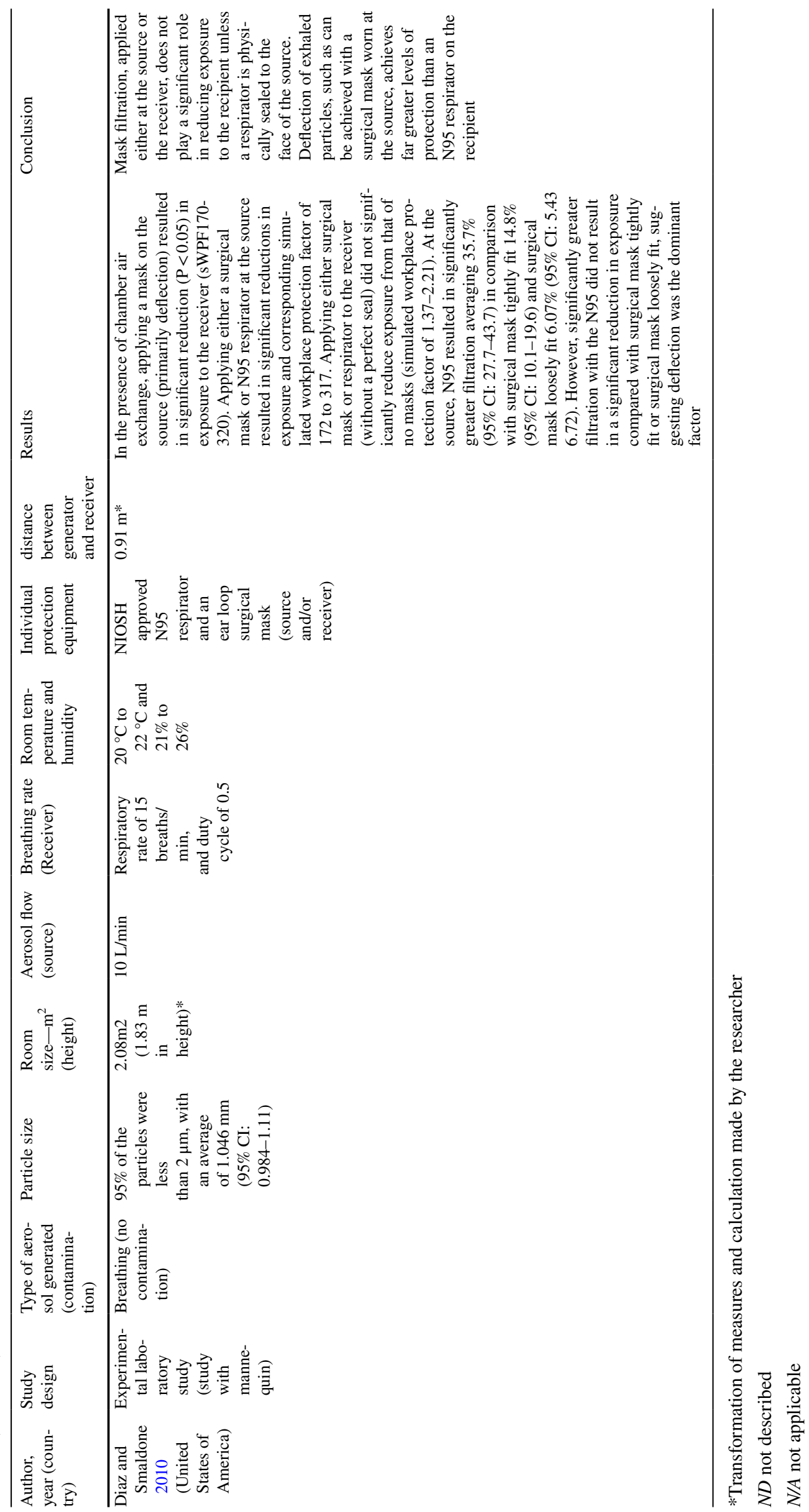




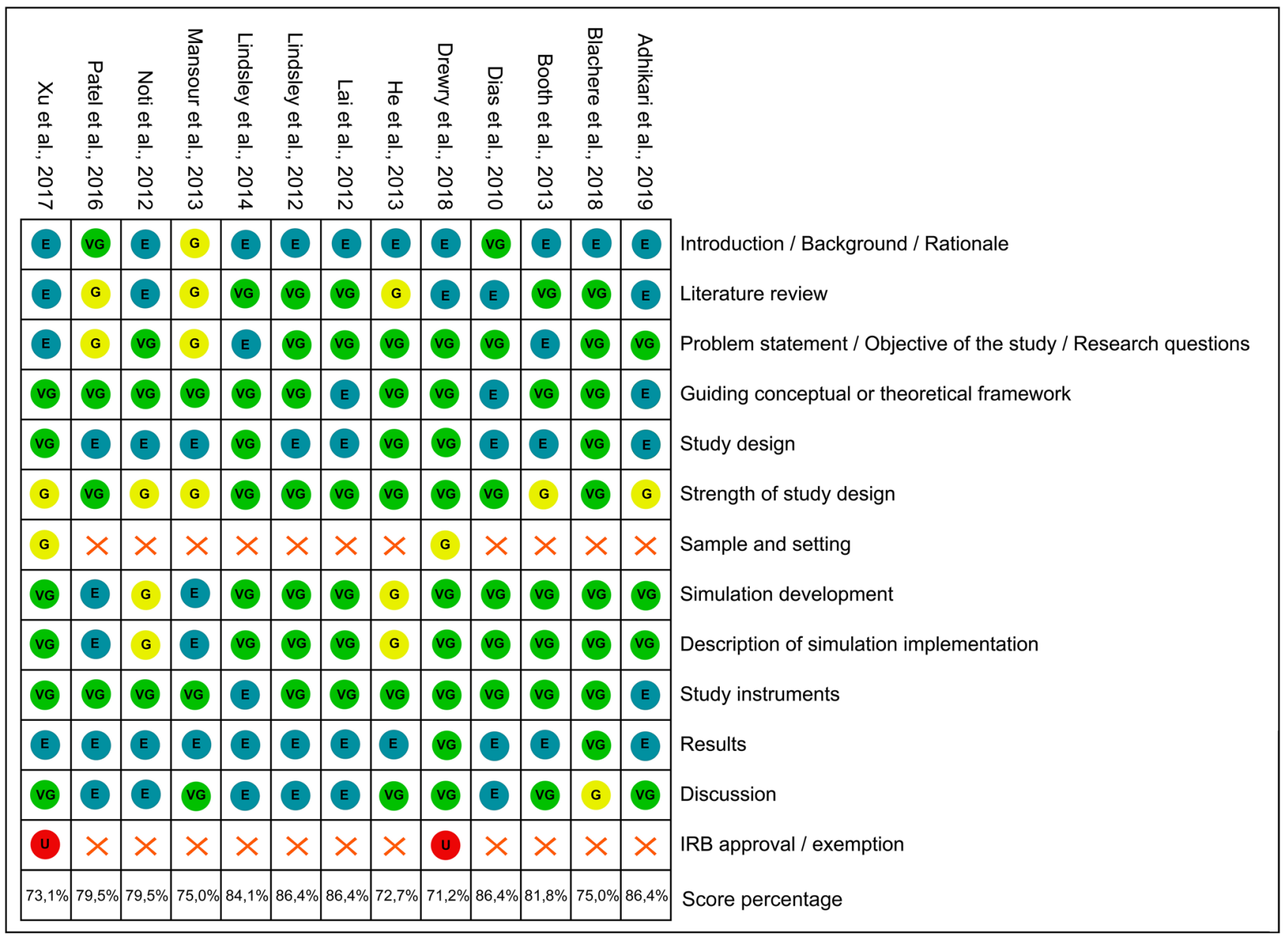

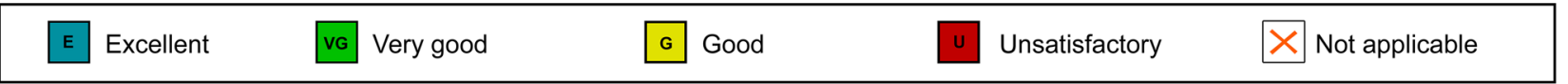

Fig. 2 Risk of bias summary: review authors' judgements about each risk of bias item for each included study

the use of a mask or respirator (even unsealed) was in the aerosol generated by coughing, but when the aerosol was generated by breathing, source control was comparable to or greater than the mask or respirator protection on the receiver (Patel et al. 2016).

The risk of contamination in closed environments was related both to the direct transmission between the aerosol and the receiver and to the indirect transmission through contact with contaminated PPEs, which is a source of infectivity retention in environments with the presence of a contaminated source (Blachere et al. 2018). In the study by Drewry et al. 2018, it was observed that transmission can occur not only near the source of the infected aerosol but also during the disposal of PPE (Drewry et al. 2018).

The aerosol generated by coughing can disperse in a plume capable of moving through a closed environment and expose people present in the environment to a highly concentrated aerosol; however, after a few minutes, a wide range of aerosol particle sizes disperse, reaching everyone in the environment (Lindsley et al. 2012). For both surgical masks and N95 respirators, the penetration of the aerosol into the filter was significantly affected by the size of the inhaled particle and the respiratory flow (He et al. 2013). Well-sealed N95 respirators provided good protection for the cough aerosol with particles of all sizes; on the other hand, surgical masks did not provide adequate protection against small particles present in cough aerosols, even when well-sealed (Lindsley et al. 2012), not being able to provide substantial protection against aerosol particles up to approximately $500 \mathrm{~nm}$ in size, in any combination of flow and respiratory rate (He et al. 2013).

The only study that evaluated the effectiveness of the face shield against exposure to a cough aerosol in a closed environment was carried out by Lindsley et al. 2014 (Lindsley et al. 2014). It was observed that the use of the face shield substantially reduced the exposure to the contaminated 
aerosol ( $96 \%$ reduction in the period immediately after the cough) and protected the respirator PPE used (97\% protection). However, face shields were less effective against smaller particles that can remain in the air for long periods and can disperse around the face shield to be inhaled. Thus, the face shield is useful as a complement; however, it should not be used as a substitute for respiratory protection.

No study has evaluated the effectiveness of using cloth masks in closed environments.

It was not possible to quantify the risk of publication bias. However, a database with other languages, such as Portuguese and Spanish, was used (Lilacs), in addition to a broader search in the gray literature, to reduce the probability of this error occurring.

\section{Discussion}

Social distancing and hand hygiene have been the main WHO recommendations to prevent the spread of SARSCoV-2; however, these measures do not prevent infection from inhaling small droplets exhaled by an infected person that can travel a distance of dozens of meters, which is a significant route of transmission indoors (Morawska and Cao 2020). It is known that SARS-CoV-2 is transmitted through contaminated fluids from the upper airways of infected people, with or without symptoms, and can spread through close contact (World Health Organization 2020a; b). The WHO suggests the use of PPE as one of the measures to prevent the spread of the disease (World Health Organization 2020a, b); however, the types of PPE are still widely discussed in terms of their effectiveness due to the wide variety of materials offered and the inefficient sealing to the face. Therefore, this systematic review proposed to address the effectiveness of masks/respirators (homemade, surgical, N95, FFP, FFP2, FFP3) or eye or facial protection, against the bioaerosol generated by individuals contaminated by infectious diseases (symptomatic or asymptomatic) in closed environments, such as the waiting rooms or exam rooms of healthcare facilities, and to extrapolate these results to the current COVID19 pandemic. The results of the qualitative synthesis of the present review demonstrate that PPE is effective in these situations; however, the results are influenced by ventilation, number of people and length of stay in the environment, the distance between the source and the receiver and the level of filtering and sealing of the mask or respirator.

SARS-CoV-2 can remain viable and infectious in aerosols for hours and on surfaces for days (van Doremalen et al. 2020) and is closely related phylogenetically to its predecessor, SARS-CoV-1 (89\% similarity) (Jalava 2020). Due to its similarity, the hypothesis that SARS-CoV-2 also spreads through the air is strengthened (Morawska and Cao 2020). Normal expiratory activities can result in aerosol generation with an 80-90\% distribution of particle size $<1 \mu \mathrm{m}$ (Morawska 2009). Expiratory droplets can carry pathogens and thus transmit diseases through the air and can be easily inhaled even after being generated (Leung et al. 2020; Lindsley et al. 2014). The results of the present review indicate that in these situations, increasing the ventilation of the environment is considered an effective measure to reduce the risk of exposure to pathogens present in contaminated bioaerosols, but it is not effective for groups exposed to a short-distance air route (Adhikari et al. 2019). Thus, in busy environments such as waiting rooms for health services, even if well ventilated, the use of masks is essential to reduce the risk of transmission.

The results of the present review indicate that the use of a surgical mask by the source of the aerosol reaches a higher level of protection than the use of the N95 respirator by the receiver (Diaz and Smaldone 2010; Mansour and Smaldone 2013; Patel et al 2016). These data suggest that traditional surgical masks are useful in preventing the transmission of respiratory diseases when applied at the source of the infected aerosol, significantly reducing the exposure of pathogens, functioning as an inhalation barrier; however, in regard to respiratory protection equipment, there are still doubts about which is the best type to be used for this purpose (Patel et al. 2016). In an environment of $27 \mathrm{~m}^{3}$ occupied by five people, although the N95 respirator promotes greater filtration, surgical masks seemed to be more effective in reducing the release of bioaerosol, a difference mainly due to the adjustment and sealing of the mask to the face of the source (Xu et al. 2017). The contribution of asymptomatic exposure to SARS-CoV-2 cases can play an important role in transmission, even in individuals who are not coughing or sneezing (Anderson et al. 2020), representing a challenge in infection control (Al-Tawfiq 2020). Because of this, during the current pandemic, the use of masks with less filtering power by all people present in the environment is more effective in reducing the risk of exposure than the use of respirators with high filtering power for only a portion of the people in the environment.

Although the mechanism for SAR-CoV-2 transmission through the eyes is not clearly understood, eye protection is recommended not only for all healthcare professionals but also for people in the risk group (Napoli et al. 2020). The qualitative synthesis of this review points to a greater risk of transmission over short distances, in which case the use of masks is essential. Face shields seem to substantially reduce exposure to a contaminated aerosol; however, they are less effective when exposed to smaller particles, so they are useful as a complement to masks and respirators (Lindsley et al. 2014). Given these results, it is indicated that health professionals working in close contact and people in the high-risk group use face shields as a way to complement the protection 
against a contaminated bioaerosol, not to eliminate the need to use a mask/respirator.

It is known that the size, speed, shape, and physical properties of the particles are factors taken into account when making masks. Even if the chosen material offers a good aerosol barrier, if it does not have a good seal on the face, then its use would not provide much protection to the individual (Davies et al. 2013). The N95 respirator showed greater filtering power, with a filtration level of approximately $95 \%$ of the aerosol particles; on the other hand, surgical masks did not provide adequate protection against small particles (Lindsley et al. 2012; Mansour and Smaldone 2013). The filtering level of the mask, whether used by the source or receiver, plays a significant role in reducing exposure only if the mask is well sealed (Diaz and Smaldone 2010). Based on these results, the provision of information sources (whether printed or digital) to patients regarding the best adjustments of the mask to the face and the importance of sealing the mask is a measure that can be taken to increase the effectiveness of this equipment in closed environments.

Despite the robustness of this review generated by the qualitative synthesis of 13 articles, some limitations should be noted. Most of these studies are experimental simulations using mannequins; therefore, the data should be viewed with caution, as their results are extrapolation to what would happen to humans. Additionally, the methodological heterogeneity of the studies prevented a quantitative analysis on the topic. It is suggested that further studies in humans be carried out, with control of the confounding variables (ventilation, number of people and length of stay in the environment, the distance between the source and the receiver, level of filtering and sealing of the mask or respirator, temperature, and humidity) to generate even more robust scientific evidence. On the other hand, the data in this review provide important information for the control of transmission, in the midst of the COVID-19 pandemic, in addition to the possibility of extrapolating these findings to any closed environment.

\section{Conclusion}

The use of mask in closed environments is effective in reducing the risk of transmission and contagion of a contaminated bioaerosol when the mask is well sealed, with greater effectiveness when these types of equipment are used by the source and receiver of the bioaerosol, regardless of the power of filtration of the equipment. Ventilation of the environment can also be performed as an auxiliary measure to reduce the risk; however, ventilation is not effective for preventing the spread of aerosols over a short distance.
Supplementary Information The online version contains supplementary material available at https://doi.org/10.1007/s00420-021-01775-y.

Author contributions CA, OG, FG, contributed to conception, design, data acquisition, drafted and critically revised the manuscript; AG and $\mathrm{BL}$, contributed to design, data analysis, drafted and critically revised the manuscript; IB, contributed to design, data acquisition, drafted and critically revised manuscript; JS, contributed to conception, data interpretation, drafted and critically revised manuscript; GR, contributed to conception, data analysis, drafted and critically revised manuscript; $\mathrm{BZ}$, contributed to design, data analysis and interpretation, drafted and critically revised manuscript; RS, contributed to conception and design, data acquisition, analysis and interpretation, drafted and critically revised manuscript. All authors gave final approval and agree to be accountable for all aspects of the work.

Funding None.

\section{Declarations}

Conflict of interest None to declare.

\section{References}

Adhikari U, Chabrelie A, Weir M, Boehnke K, McKenzie E, Ikner L, Wang M, Wang Q, Young K, Haas CN, Rose J, Mitchell J (2019) A case study evaluating the risk of infection from middle eastern respiratory syndrome coronavirus (MERS-CoV) in a hospital setting through bioaerosols. Risk Anal 39:2608-2624. https://doi. org/10.1111/risa.13389

Al-Tawfiq JA (2020) Asymptomatic coronavirus infection: MERS-CoV and SARS CoV-2 (COVID-19). Travel Med Infect Dis. https://doi. org/10.1016/j.tmaid.2020.101608

Anderson EL, Turnham P, Griffin JR, Clarke CC (2020) Consideration of the aerosol transmission for COVID-19 and public health. Risk Anal 40:902-907. https://doi.org/10.1111/risa.13500

Bartoszko JJ, Farooqi MAM, Alhazzani W, Loeb M (2020) Medical masks vs N95 respirators for preventing COVID-19 in healthcare workers: a systematic review and meta-analysis of randomized trials. Influenza Other Respir Viruses. https://doi.org/10.1111/ irv. 12745

Blachere FM, Lindsley WG, McMillen CM, Beezhold DH, Fisher EM, Shaffer RE, Noti JD (2018) Assessment of influenza virus exposure and recovery from contaminated surgical masks and N95 respirators. J Virol Methods 260:98-106. https://doi.org/10.1016/j. jviromet.2018.05.009

Booth CM, Clayton M, Crook B, Gawn JM (2013) Effectiveness of surgical masks against influenza bioaerosols. J Hosp Infect 84(1):2226. https://doi.org/10.1016/j.jhin.2013.02.007

Cegolon L (2020) Investigating hypothiocyanite against SARS-CoV-2. Int J Hyg Environ Health 227:113520. https://doi.org/10.1016/j. ijheh.2020.113520

Centers for disease control and prevention (2016) Prevention strategies for seasonal influenza in healthcare settings. Guidelines and Recommendations. CDCP. Available at: https://www.cdc.gov/flu/ professionals/infectioncontrol/healthcaresettings.htm. Accessed 28 May 2020

Chen YC, Huang LM, Chan CC, Su CP, Chang SC, Chang YY, Chen ML, Hung CC, Chen WJ, Lin FY, Lee YT, National Taiwan University, H (2004) SARS in hospital emergency room. Emerg Infect Dis 10:782-788. https://doi.org/10.3201/eid1005.030579 
Davies A, Thompson KA, Giri K, Kafatos G, Walker J, Bennett A (2013) Testing the efficacy of homemade masks: would they protect in an influenza pandemic? Disaster Med Public Health Prep 7:413-418. https://doi.org/10.1017/dmp.2013.43

Diaz KT, Smaldone GC (2010) Quantifying exposure risk: surgical masks and respirators. Am J Infect Control 38:501-508. https:// doi.org/10.1016/j.ajic.2010.06.002

Drewry DG 3rd, Sauer LM, Shaw-Saliba K, Therkorn J, RainwaterLovett K, Pilholski T, Garibaldi BT (2018) Identifying potential provider and environmental contamination on a clinical biocontainment unit using aerosolized pathogen simulants. Health Secur 16:83-91. https://doi.org/10.1089/hs.2017.0064

Faridi S, Niazi S, Sadeghi K, Naddafi K, Yavarian J, Shamsipour M, Jandaghi NZS, Sadeghniiat K, Nabizadeh R, Yunesian M, Momeniha F, Mokamel A, Hassanvand MS, MokhtariAzad T (2020) A field indoor air measurement of SARS-CoV-2 in the patient rooms of the largest hospital in Iran. Sci Total Environ 725:138401. https://doi.org/10.1016/j.scitotenv.2020.138401

Gralton J, Tovey E, McLaws ML, Rawlinson WD (2011) The role of particle size in aerosolised pathogen transmission: a review. J Infect 62:1-13. https://doi.org/10.1016/j.jinf.2010.11.010

He X, Reponen T, McKay RT, Grinshpun SA (2013) Effect of particle size on the performance of an N95 filtering facepiece respirator and a surgical mask at various breathing conditions. Aerosol Sci Technol 47:1180-1187. https://doi.org/10.1080/02786826.2013. 829209

Jalava K (2020) First respiratory transmitted food borne outbreak? Int J Hyg Environ Health 226:113490. https://doi.org/10.1016/j.ijheh. 2020.113490

Lai AC, Poon CK, Cheung AC (2012) Effectiveness of facemasks to reduce exposure hazards for airborne infections among general populations. J R Soc Interface 9:938-948. https://doi.org/10.1098/ rsif.2011.0537

Larson EL, Liverman CT (eds) (2011) Institute of medicine (US) committee on personal protective equipment for healthcare personnel to prevent transmission of pandemic influenza and other viral respiratory infections: Current research issues. Preventing transmission of pandemic influenza and other viral respiratory diseases: Personal protective equipment for healthcare personnel: Update 2010. Washington (DC): National Academies Press (US), PMID: 24983058

Leung NHL, Chu DKW, Shiu EYC, Chan KH, McDevitt JJ, Hau BJP, Yen HL, Li Y, Ip DKM, Peiris JSM, Seto WH, Leung GM, Milton DK, Cowling BJ (2020) Respiratory virus shedding in exhaled breath and efficacy of face masks. Nat Med. https://doi.org/10. 1038/s41591-020-0843-2

Lindsley WG, King WP, Thewlis RE, Reynolds JS, Panday K, Cao G, Szalajda JV (2012) Dispersion and exposure to a cough-generated aerosol in a simulated medical examination room. J Occup Environ Hyg 9:681-690. https://doi.org/10.1080/15459624.2012. 725986

Lindsley WG, Noti JD, Blachere FM, Szalajda JV, Beezhold DH (2014) Efficacy of face shields against cough aerosol droplets from a cough simulator. J Occup Environ Hyg 11:509-518. https://doi. org/10.1080/15459624.2013.877591

Loeb M, Dafoe N, Mahony J, John M, Sarabia A, Glavin V, Webby R, Smieja M, Earn DJ, Chong S, Webb A, Walter SD (2009) Surgical mask vs N95 respirator for preventing influenza among health care workers: a randomized trial. JAMA 302:1865-1871. https://doi. org/10.1001/jama.2009.1466

Long Y, Hu T, Liu L, Chen R, Guo Q, Yang L, Cheng Y, Huang J, Du L (2020) Effectiveness of N95 respirators versus surgical masks against influenza: a systematic review and meta-analysis. J Evid Based Med. https://doi.org/10.1111/jebm.12381
Mansour MM, Smaldone GC (2013) Respiratory source control versus receiver protection: impact of facemask fit. J Aerosol Med Pulm Drug Deliv 26:131-137. https://doi.org/10.1089/jamp.2012.0998

Moher DA, JenniferAltman DG (2009) Preferred reporting items for systematic reviews and meta-analyses: the PRISMA statement. Int J Surg 62:7. https://doi.org/10.1016/j.ijsu.2010.02.007

Morawska L, Cao J (2020) Airborne transmission of SARS-CoV-2: the world should face the reality. Environ Int 139:105730. https://doi. org/10.1016/j.envint.2020.105730

Morawska LJG, Ristovski ZD, Hargreaves M, Mengersen K, Corbett $S$ et al (2009) Size distribution and sites of origin of droplets expelled from the human respiratory tract during expiratory activities. J Aerosol Sci 40(43):256-269. https://doi.org/10.1016/j.jaero sci.2008.11.002

Napoli PE, Nioi M, d'Aloja E, Fossarello M (2020) The ocular surface and the coronavirus disease 2019: does a dual 'ocular route' exist? J Clin Med. https://doi.org/10.3390/jcm9051269

Noti JD, Lindsley WG, Blachere FM, Cao G, Kashon ML, Thewlis RE, McMillen CM, King WP, Szalajda JV, Beezhold DH (2012) Detection of infectious influenza virus in cough aerosols generated in a simulated patient examination room. Clin Infect Dis 54:1569-1577. https://doi.org/10.1093/cid/cis237

Offeddu V, Yung CF, Low MSF, Tam CC (2017) Effectiveness of masks and respirators against respiratory infections in healthcare workers: a systematic review and meta-analysis. Clin Infect Dis 65:1934-1942. https://doi.org/10.1093/cid/cix681

Patel RB, Skaria SD, Mansour MM, Smaldone GC (2016) Respiratory source control using a surgical mask: an in vitro study. J Occup Environ Hyg 13:569-576. https://doi.org/10.1080/15459 624.2015.1043050

Shiu EYC, Leung NHL, Cowling BJ (2019) Controversy around airborne versus droplet transmission of respiratory viruses: implication for infection prevention. Curr Opin Infect Dis 32:372-379. https://doi. org/10.1097/QCO.0000000000000563

Siegel JD, Rhinehart E, Jackson M, Chiarello L, Health Care Infection Control Practices Advisory (2007) 2007 Guideline for isolation precautions: preventing transmission of infectious agents in health care settings. Am J Infect Control 35:65-164. https://doi.org/10.1016/j.ajic. 2007.10.007

Smith JD, MacDougall CC, Johnstone J, Copes RA, Schwartz B, Garber GE (2016) Effectiveness of N95 respirators versus surgical masks in protecting health care workers from acute respiratory infection: a systematic review and meta-analysis. CMAJ 188:567-574. https://doi. org/10.1503/cmaj.150835

Tellier R (2019) Recognition of aerosol transmission of infectious agents: a commentary. BMC Infect Dis 19:101. https://doi.org/10.1186/ s12879-019-3707-y

van Doremalen N, Bushmaker T, Morris DH, Holbrook MG, Gamble A, Williamson BN, Tamin A, Harcourt JL, Thornburg NJ, Gerber SI, Lloyd-Smith JO, de Wit E, Munster VJ (2020) Aerosol and surface stability of SARS-CoV-2 as compared with SARS-CoV-1. N Engl J Med 382:1564-1567. https://doi.org/10.1056/NEJMc2004973

Verbeek JH, Rajamaki B, Ijaz S, Sauni R, Toomey E, Blackwood B, Tikka C, Ruotsalainen JH, Kilinc Balci FS (2020) Personal protective equipment for preventing highly infectious diseases due to exposure to contaminated body fluids in healthcare staff. Cochrane Database Syst Rev 4:CD011621. https://doi.org/10.1002/14651858.CD011621.pub2

World Health Organization, e.a., (2020) Modes of transmission of virus causing COVID 19: implications for IPC precaution recommendations. WHO Scientific brief. Available at: https://www.who.int/newsroom/commentaries/detail/modes-of-transmission-of-virus-causingcovid-19-implications-for-ipc-precaution-recommendations. Accessed 28 May 2020

World Health Organization (2020) Advice on the use of masks in the context of COVID-19: interim guidance; WHO. Available at: https://www. who.int/publications/i/item/ 
advice-on-the-use-of-masks-in-the-community-during-home-careand-in-healthcare-settings-in-the-context-of-the-novel-coronavirus(2019-ncov)-outbreak. Accessed 28 May 2020

Xu C, Wu C-Y, Yao M (2017) Fluorescent bioaerosol particles resulting from human occupancy with and without respirators. Aerosol Air Quality Res 17:198-208. https://doi.org/10.4209/aaqr.2016.09.0400
Publisher's Note Springer Nature remains neutral with regard to jurisdictional claims in published maps and institutional affiliations. 